\title{
Abundance and Foraging Behaviour of Entomophilous Pollinators on Sesame, Sesamum indicum L.
}

\author{
G. Selvakumari, B. Usha Rani ${ }^{\star 1}$, K. Suresh ${ }^{2}$, G. Anand ${ }^{2}$ and M. Shanthi \\ Department of Agricultural Entomology, \\ Agricultural College and Research Institute, Tamil Nadu Agricultural University, Madurai-625 104, India \\ ${ }^{1}$ ICAR- Krishi Vigyan Kendra, in code, India \\ ${ }^{2}$ Cotton Research Station, Srivilliputhur-626 125, India \\ *E-mail: ushateja@yahoo.com
}

\begin{abstract}
The present study focused on the community of insect pollinators, abundance and foraging behavior of different pollinators on sesame. During the study period 32 species of insect visitors were observed in sesame. The order Hymenoptera shared maximum abundance $(81.25 \%)$ followed by Diptera $(12.50 \%)$ and Coleoptera (6.25\%). Among them Apis dorsata acted as dominant forager contributing $24.72 \%$ followed by Apis cerana indica (22.44\%) and Apis florea (11.29\%). Most of the bees visited sesame flowers, but the density of $A$. dorsata, $A$. c. indica was maximum and peaked during $1000-1200$ hours with a mean population of 14.06 and 12.0 individuals $/ \mathrm{m}^{2} / 5$ min whereas the activity of $A$. florea peaked ( 7.05 individuals $/ \mathrm{m}^{2} / 5 \mathrm{~min}$ ) at 0800-1000 hours and a steady decline in abundance of bees was observed during evening hours. The flower visitation frequency was found maximum ( 9.14 flowers $/ \mathrm{min}$ ) in $A$. c c indica followed by $A$. dorsata $(7.44 \mathrm{flowers} / \mathrm{min}) \mathrm{during}$ 1000- 1200 hours meanwhile the sequence of flower visitation reduces during evening $1600-1800$ hours as 3.12 and 3.18 flowers/ min respectively. The time spent by different bees was in the order $A$. florea (18.05 sec/ flower) $>A$. cerana (15.04 sec/flower) $>A$. dorsata $(11.14$ sec/flower) between 0600-0800 hours.
\end{abstract}

Keywords: Apis cerana indica, Abundance, Foraging behaviour, Foraging rate, Pollinator, Sesamum indicum

The edible oil plays a crucial role in stabilization of human health. India shares an eminent place in global oilseeds production with $12-15$ per cent of cultivation area and 9-10 per cent of the total edible oil consumption. Sesame Sesamum idicum $\mathrm{L}$. belongs to the family Pedaliaceae is one of the oldest oil seed crop and indigenous to Africa due to the preponderance of wild species in that region (Azeez et al 2017). It ranks third among the world nine major edible oil seed crop after groundnut and mustard (Rakesh et al 2017) Next to Sudan, India cruises 14.31 percent of sesame production to global market. In Tamil Nadu, sesame is cultivated in an area of 0.446 lakh ha with a production of 0.244 lakh tones and productivity of $548 \mathrm{~kg}$ per ha (Anonymous 2020) The complimentary pollination carried out by honey bees in sesame improves seed germination, vigour of seeds and augments the crop yield to an extent of 22 to 33 percent. Insect pollinators serve as the effective source for enhancing the crop yield both qualitatively and quantitatively (Patidar et al 2017). It is estimated that global annual economic value of insect pollination is $€ 153$ billion (Das and Jha 2018). Being a self-pollinated crop the tubular floral structure of sesame facilitates cross pollination up to an extent of 65 percent (Kamel et al 2013). Hence this basic research was carried out to document the pollinator fauna and abundance of insect pollinators in sesamum.

\section{MATERIAL AND METHODS}

The experimental trial was laid out at Agricultural College and Research Institute $\left(9.96^{\circ} \mathrm{N}, 78.20^{\circ} \mathrm{E}\right)$, Madurai during March - May 2021 to study the diversity of insect pollinators, foraging behavior, relative abundance, foraging rate and speed of insect pollinators on sesame. The experimental plot was laid out in randomized block design. The number of insect pollinators from each species visiting sesame flowers were recorded from 10 percent flowering stage of the crop to flowering cessation period and were collected using sweep net, subsequently killed and preserved in ethanol for identification. The foraging behavior of insect pollinators was observed for 5 minutes from 0600 1800 hours at two hours interval in five plants during alternate flowering days and expressed as mean No. of individuals $/ \mathrm{m}^{2} / 5 \mathrm{~min}$ (Das and Jha, 2019). The relative abundance of insect pollinators was calculated as Population of particular species Relative abundance $(\%)=\frac{\text { visiting flowers }}{\begin{array}{c}\text { Total population of all species } \\ \text { visiting flowers }\end{array}} \times 100$

Total population of all species visiting flowers

The foraging rate (mean no. of flowers visited / minute) 
and foraging speed (time spent/ flower/minute) of insect pollinators were counted using electronic stop watch at two hours interval from 0600-1800 hours for five sunny days (Pashte and Shylesha, 2013). During the experimental period the cropping area was free from chemical applications to allow the frequency of natural pollinators. The data obtained were analysed using descriptive statistics and SPSS software package.

\section{RESULTS AND DISCUSSION}

Pollinator fauna: The sesame flowers attracted diverse group of insect visitors. A sum of 32 insect visitors belonging to four different orders such as Hymenoptera (16 species), Lepidoptera (8 species), Diptera (6 species) and Coleoptera (2 species) (Table 1, Fig. 1) In that 16 species of Hymenoptera 13 species was identified from seven different families such as Apidae, Megachilidae, Halictidae, Xylocopidae and Crabronidae, Formicidae and Chrysididae. In Hymenoptera the family Apidae was most abundant with six species namely $A$. dorsata, $A$. cerana indica, $A$. florea, Ceratina sp., Braunsapis sp. and Amegilla zonata. It was followed by the family Megachilidae, which shared three species Megachile lanata, Megachile disjuncta and Anthidum sp. However the family Xylocopidae and Halictidae contributes two species. Next to Hymenoptera the order of diversity was followed by Lepidoptera comprising eight species from four families namely, Nymphalidae, Pieridae, Papilionidae and Lycaenidae. Most of the insects visit sesame flowers for collecting pollen or nectar but those who carry considerable amount of pollen grains on their body were considered as pollinators and remaining insect visitors were considered as flower visitors, a visual observation was made to record foraging activity of insect foragers on pollen and nectar to substantiate the role of flower visitors in pollination service (Table 2).

Insect pollinators with their activity of extending their proboscis into the flowers were considered as nectar collectors and those carrying pollen on their hind legs were determined as pollen collectors. In the sesamum ecosystem only 16 species were confined as pollinators. Lepidoptera shares maximum species than Dipteran but did not have significant role in pollination service as they mainly gather only nectar by extending their proboscis. Due to the tubular floral structure of sesame flowers sometimes they probe over the corolla or by holding them to suck the nectar present inside the extra nectaral disc surrounding the ovary that does not aid in adhering of pollen grains as like sunflower, mustard, to their legs whereas Dipterans flight over the flowers to collect the floral rewards abundantly as like Hymenopterans. Mahfouz et al (2012) reported Hymenoptera, Diptera,
Lepidoptera and Coleoptera where the order Hymenoptera pertains to maximum number of pollinators (Pashte et al 2013) witnessed 22 species of insect pollinators foraged on sesame flowers. Among them Hymenoptera shared 17 species associated by three species from Diptera and two species from Lepidoptera. Kamel et al (2013) recorded 29

Table 1. Flower visitors of sesame (Sesamum indicum L.) during 2020-21

\begin{tabular}{|c|c|c|}
\hline Common name & Scientific name & Family \\
\hline \multicolumn{3}{|l|}{ Hymenoptera } \\
\hline Indian bee & Apis cerana indica & Apidae \\
\hline Rock bee & Apis dorsata & Apidae \\
\hline Little bee & Apis florea & Apidae \\
\hline Small carpenter bee & Ceratina sp. & Apidae \\
\hline Blue banded bee & Amegilla zonata & Apidae \\
\hline Reed bee & Braunsapis sp. & Apidae \\
\hline Large carpenter bee & Xylocopa sp. 1 & Xylocopidae \\
\hline Large carpenter bee & Xylocopa sp. 2 & Xylocopidae \\
\hline Wooly wall bee & Megachile lanata & Megachilidae \\
\hline Resin bee & Megachile disjuncta & Megachilidae \\
\hline Wool carder bee & Anthidium sp. & Megachilidae \\
\hline Sweat bee & Halictus sp. & Halictidae \\
\hline Sweat bee & Nomia sp. & Halictidae \\
\hline Wasp & Unidentified & Crabronidae \\
\hline Cuckoo wasp & Stilbum cyanurum & Chrysididae \\
\hline Black ant & Camponotus sp. & Formicidae \\
\hline \multicolumn{3}{|l|}{ Diptera } \\
\hline Hoverfly & Eristalinus sp. & Syrphidae \\
\hline Marmalade hover fly & Episyrphus sp. & Syrphidae \\
\hline Green tailed fly & Hedriodiscus sp. & Stratiomyidae \\
\hline Robber fly & Unidentified & Asilidae \\
\hline House fly & Musca sp. & Muscidae \\
\hline Blow fly & Lucilia sp. & Calliphoridae \\
\hline \multicolumn{3}{|l|}{ Lepidoptera } \\
\hline Monarch butterfly & Danaus chryssipus & Nymphalidae \\
\hline Tawny coster & Acraea terpsicore & Nymphalidae \\
\hline Blue pansy & Junonia sp. & Nymphalidae \\
\hline Cabbage butterfly & Pieris brassicae & Pieridae \\
\hline Orange tip butterfly & Anthocharis cardamine & Pieridae \\
\hline Citrus butterfly & Papilio demoleus & Papilionidae \\
\hline Swallow tail & Papilio polytes & Papilionidae \\
\hline Pulse blue butterfly & Lampides boeticus & Lycaenidae \\
\hline \multicolumn{3}{|l|}{ Coleoptera } \\
\hline Chaffer beetle & Oxycetonia versicolor & Scarabaeidae \\
\hline Pumpkin beetle & Aulacophora foveocolis & Chrysomelidae \\
\hline
\end{tabular}


species of insect pollinators in sesame flowers, in which the order Hymenoptera contributed 18 species, followed by seven species from the order Diptera, three species from Lepidoptera and one species from Coleoptera. Ngongolo et al 2015) reported 24 species of insect visitor aids in pollination service of sesame. Meanwhile, Das and Jha 2019) recorded minimum pollinators in sesame holding 10 insect visitors belonging to the order Hymenoptera comprising of five species viz., A. dorsata, A. mellifera, Megachile sp., Vespa cincta and Camponotus sericius followed by Diptera holding two species viz., Sacrocophaga sp. and $M$. domestica and Lepidoptera comprising three species viz., D. chrycippus, Amata bicincta and Pieris sp.

Foraging behaviour: Due to the presence of sufficient sunshine hours the foraging activity of $A$. dorsata and $A$. $c$. indica was maximum at 1000- 1200 hours and drastically reduced during evening $1600-1800$ hours. The activity of $A$. florea was peaked at 0800- 1000 hours with 7.05 individuals $/ \mathrm{m}^{2} / 5 \mathrm{~min}$. During 0800- 1000 hours, Ceratina sp. act as the most abundant pollinator with 2.74 individuals $/ \mathrm{m}^{2} /$ 5 min while its activity was nil between 1200-1400 hours. 1000-1200 hours was the predominant time for foraging on sesame flowers by $A$. zonata whereas very low activity was observed at $1400-1600$ hours. The dominance of Braunsapis $\mathrm{sp}$. was during 1000-1200 hours with 3.76 individuals $/ \mathrm{m}^{2} / 5$ min. Both the Xylocopa sp. started their foraging on $0800-$ 1000 hours and actively foraged on flowers at 1200- 1400 hours. The bounciness of Megachillid bees, $M$. lanata and $M$. disjuncta was soared at 1000-1200 hours. However a slow decline on individuals of $M$. lanata was recorded at 1200 1400 hours and complete cessation of $M$. disjuncta during 1200- 1800 hours. The activity of unidentified Hymenopteran, initiated at $0800-1000$ hours spired at $1000-$ 1200 hours and terminated at 1200- 1400 hours. The foraging period of Halictid bees namely Halictus sp. and Nomia sp. on sesame flowers was maximum at 1000-1200 hours. Dipteran flies, Eristalinus sp. and Episyrphus sp. showed maximum abundance at 0800- 1000 hours and 1000-1200 hours respectively (Table 3 ). When the sesame flowers are exposed with adequate pollen and nectar source the difference in densities of pollinators on flowers occurs. The longer lower lip of sesame flowers is kept folded over the short upper lip until the flower opening which takes place usually around 0630 hours. As soon as opened, it provides running strip for bees and they blemishes over the foraging rewards in peak hours. Later, the tender flowers slowly closes their floral openings in late sunshine hours restricting the movement of bees thereby reporting low densities of individuals in evening hours. In the present study, the abundance of $A$. dorsata was maximum in the experimental
Table 2. Major floral pollinators of sesame in AC \& RI, Madurai

\begin{tabular}{llcc}
\hline Pollinators & Family & \multicolumn{2}{c}{ Collection of } \\
\cline { 2 - 4 } & & Pollen $^{*}$ & Nectar $^{*}$ \\
\hline A. c. indica & Apidae & + & + \\
A. dorsata & Apidae & + & + \\
A. florea & Apidae & + & + \\
Ceratina sp. & Apidae & + & + \\
A. zonata & Apidae & + & + \\
Braunsapis sp. & Apidae & + & + \\
Xylocopa sp. 1. & Xylocopidae & + & + \\
Xylocopa sp. 2. & Xylocopidae & + & + \\
M. lanata & Megachilidae & + & - \\
M. disjuncta & Megachilidae & + & - \\
Halictus sp. & Halictidae & + & + \\
N. crassipes & Halictidae & + & - \\
Unidentified & Crabronidae & - & + \\
Eristalinus sp. & Syrphidae & - & + \\
Episyrphus sp. & Syrphidae & - & + \\
O. versicolor & Scarabaeidae & + & - \\
\hline
\end{tabular}

*+ collected, - did not collect

site this was mainly due to the presence of adequate number of natural hives in nearby locations. Mahfouz et al (2012) recorded the maximum and minimum activity of honey bees at 0900- 1100 hours and 1500-1600 hours respectively. They also observed that abundance of bee activity decreased with diminishing flowers per plant due to the increase in age of the crop. Bhagawati and Rahman (2016) observed the foraging behaviour of $A$. cerana on sesame and concluded that 0900 1000 hours was the peak period of visitation that is concurred with our present study results.

Relative abundance of pollinators: The relative abundance of various insect pollinators was in the order Hymenoptera $(81.25 \%)>$ Diptera $(12.50 \%)>$ Coleoptera $(6.25 \%)$ (Fig. 2).

The share of abundance contributed by Apis and Non Apis was 37.50 and 43.75 per cent respectively. A. dorsata was considered as dominant forager is representing an average population of 7.05 individuals $/ \mathrm{m}^{2}$ constituting $24.72 \%$ of total insect pollinators. This was followed by $A$. $c$. indica composing $22.44 \%$ of insect fauna whereas the $A$. florea showed less abundance of $11.29 \%$. The Ceratina sp. exhibited $3.01 \%$ of abundance. Meanwhile Braunsapis sp. from the family Apidae shared 5.20 per cent abundance. The abundance of Halictus sp. and Nomia sp. was 6.80 and 3.26 percent followed by Megachillid bees, $M$. lanata and $M$. disjuncta shared 1.64 and 1.43 per cent of dominance among the pollinators respectively. Both the Xylocopa sp. occupied 
1.71 and $1.64 \%$ share of insect visitors. Among $12.50 \%$ shared by the order Diptera, the Eristalinus sp. and Episyrphus sp. recorded 3.43 and 4.62 percent abundance. Coleoptera is the least abundant order where Oxycetonia versicolor contributed 1.50 percent (Table 4, Fig. 2). The population of pollinator increased in subsequent flowering period. On reaching the peak flowering period the abundance of pollinators gradually declined due to the cessation of flowers. It was stated that during the peak flowering period the abundance of pollinators were 43.55 insects $/ \mathrm{m}^{2}$ but at the time of cessation of flowers the pollinator abundance was reduced to 18.63 insects $/ \mathrm{m}^{2}$.

The abundance of $A$. dorsata was maximum (24.72\%) during the course of study might be due to the natural nest congregation in the experimental area. The presence of suitable environmental condition and the availabilty of floral rewards like attractive colour, pollens from freshly opened flowers, copious flow of nectar throughout the foraging period strongly influence the dominance of pollinator species. Kamel et al (2013) observed abundance of order Hymenoptera was higher in two consecutive study seasons of sesame flowering period (90.94 and 89.59 ) followed by Diptera (3.93 and 5.38), Lepidoptera (3.58 and 3.62) whereas the least percent abundance was shared by order Coleoptera (1.53 and 1.39). Bhagwati and Rahman (2016) reported that $A$. cerana as dominant forager (32.66\%) adhered by $A$. dorsata (26.54\%) and $A$. florea (4.76\%) during the entire blooming period of sesame. The present reports are in close relation with Das and Jha (2019) where they documented, the abundance of Hymenoptera was $89.87 \%$ followed by Diptera (6.47\%).

Foraging rate: During 0800-1000 hours, A. c. indica visited more number of flowers ( 9.14 flowers / min) besides $A$. dorsata visited 7.44 flowers/ $\mathrm{min}$ as freshly opened flowers are maximum during morning hours however their activity drastically reduced in evening hours (3.12 and 3.18 flowers /

Table 3. Foraging behaviour of pollinators on sesame (AC\&RI, Madurai)

\begin{tabular}{|c|c|c|c|c|c|c|c|}
\hline \multirow[t]{2}{*}{ Pollinators } & \multicolumn{7}{|c|}{${ }^{*}$ Mean No. of individuals $/ \mathrm{m}^{2} / 5 \mathrm{~min}$} \\
\hline & 0600-0800 & $0800-1000$ & $1000-1200$ & $1200-1400$ & $1400-1600$ & $1600-1800$ & Mean \\
\hline \multicolumn{8}{|l|}{ Apis bees } \\
\hline \multicolumn{8}{|l|}{ Hymenopterans } \\
\hline A. c. indica & $5.06^{a}$ & $8.13^{b}$ & $12^{\mathrm{b}}$ & $7.04^{\mathrm{a}}$ & $4.13^{\mathrm{b}}$ & $2.06^{\mathrm{b}}$ & 6.40 \\
\hline A. dorsata & $5.05^{\mathrm{b}}$ & $9.05^{\mathrm{a}}$ & $14.06^{\mathrm{a}}$ & $6.08^{\mathrm{b}}$ & $5.05^{\mathrm{a}}$ & $3.04^{\mathrm{a}}$ & 7.05 \\
\hline A. florea & $2.17^{\circ}$ & $7.05^{\circ}$ & $5.04^{\circ}$ & $3.25^{\circ}$ & $1.01^{\mathrm{d}}$ & $0.8^{\mathrm{c}}$ & 3.22 \\
\hline Braunsapis sp. & $0.00^{9}$ & $2.66^{\mathrm{de}}$ & $3.76^{\mathrm{e}}$ & $1.94^{\mathrm{e}}$ & $0.65^{\mathrm{e}}$ & $0.00^{\mathrm{h}}$ & 1.50 \\
\hline A. zonata & $1.26^{d}$ & $2.42^{\text {ef }}$ & $4.15^{\mathrm{d}}$ & $1.14^{h}$ & $0.3^{f}$ & $0.11^{9}$ & 1.56 \\
\hline Ceratina sp. & $0.00^{9}$ & $2.74^{d}$ & $1.51^{\mathrm{i}}$ & $0.00^{\prime}$ & $0.61^{\mathrm{e}}$ & $0.30^{\mathrm{e}}$ & 0.86 \\
\hline Mean & 2.25 & 5.34 & 6.75 & 3.24 & 1.95 & 1.05 & 3.43 \\
\hline \multicolumn{8}{|l|}{ Non- apis bees } \\
\hline Halictus sp. & $0.69^{f}$ & $2.86^{\mathrm{d}}$ & $3.74^{9}$ & $2.44^{d}$ & $1.41^{\mathrm{c}}$ & $0.14^{f}$ & 1.94 \\
\hline Nomia sp. & $1.09^{\mathrm{e}}$ & $2.14^{9}$ & $3.21^{n}$ & $1.21^{\mathrm{h}}$ & $0.00^{f}$ & $0.29^{\mathrm{e}}$ & 0.93 \\
\hline Xylocopa sp. 1 & $0.00^{9}$ & $0.06^{m}$ & $1.14^{\prime}$ & $1.61^{f}$ & $0.01^{f}$ & $0.00^{h}$ & 0.47 \\
\hline Xylocopa sp. 2 & $0.00^{9}$ & $0.08^{m}$ & $1.41^{\mathrm{j}}$ & $1.45^{\mathrm{g}}$ & $0.00^{f}$ & $0.00^{h}$ & 0.49 \\
\hline M. disjuncta & $0.00^{9}$ & $1.05^{\mathrm{i}}$ & $1.43^{\mathrm{ij}}$ & $0.00^{\circ}$ & $0.00^{f}$ & $0.00^{\mathrm{h}}$ & 0.41 \\
\hline M. lanata & $0.00^{9}$ & $0.77^{\mathrm{j}}$ & $1.26^{\mathrm{k}}$ & $0.92^{i}$ & $0.00^{f}$ & $0.00^{\mathrm{h}}$ & 0.49 \\
\hline Unidentified & $0.00^{9}$ & $0.49^{\mathrm{jk}}$ & $1.30^{k}$ & $0.57^{k}$ & $0.00^{f}$ & $0.16^{f}$ & 0.43 \\
\hline Mean & 0.25 & 1.06 & 1.78 & 1.36 & 0.23 & 0.09 & 0.79 \\
\hline \multicolumn{8}{|l|}{ Dipterans } \\
\hline Eristalinus sp. & $1.08^{e}$ & $2.06^{h}$ & $0.90^{n}$ & $1.17^{\mathrm{h}}$ & $0.68^{\mathrm{e}}$ & 0.00 & 0.98 \\
\hline Episyrphus sp. & $0.45^{f}$ & $2.04^{h}$ & $3.06^{f}$ & $1.53^{\mathrm{g}}$ & $0.84^{d}$ & 0.00 & 1.32 \\
\hline Mean & 0.76 & 2.05 & 1.98 & 1.35 & 0.76 & 0.00 & 1.15 \\
\hline \multicolumn{8}{|l|}{ Coleopteran } \\
\hline O. versicolor & 0.00 & 0.17 & 0.47 & 0.63 & 0.67 & 0.67 & 0.43 \\
\hline
\end{tabular}


min during 1600- 1800 hours respectively) (Table 5). $A$. florea visited 5.95 flowers/ min during 1000-1200 hours and their foraging activity was minimum during afternoon 1600 1800 hours (1.54 flowers/ $\mathrm{min}$ ). Higher the foraging rate may enhance the efficiency of pollination.

Decline in foraging rate of honeybees in evening hours

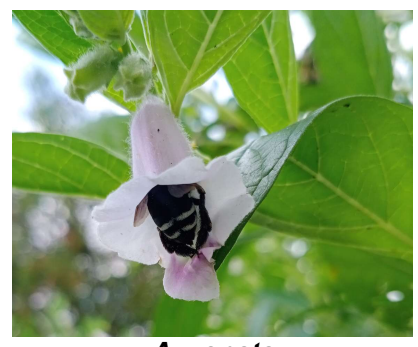

A. zonata

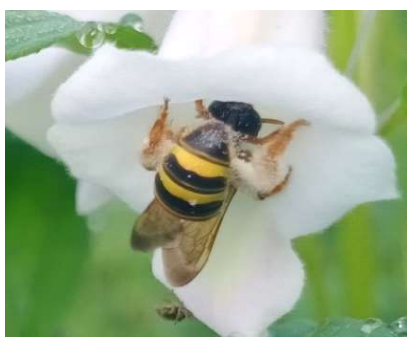

Nomia sp.

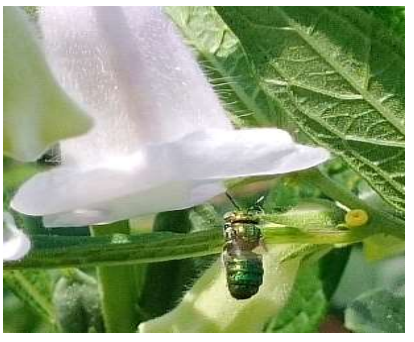

Halictus sp.

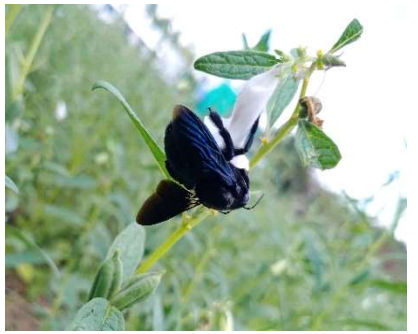

Xylocopa sp. 1

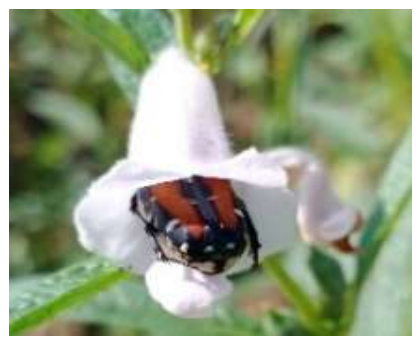

O. versicolor

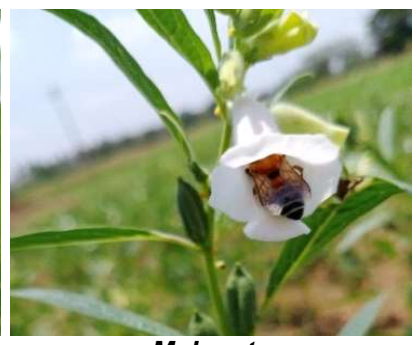

M. lanata

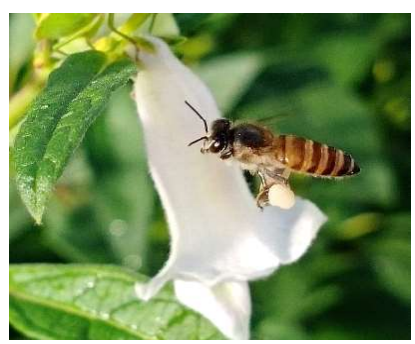

A c. indica

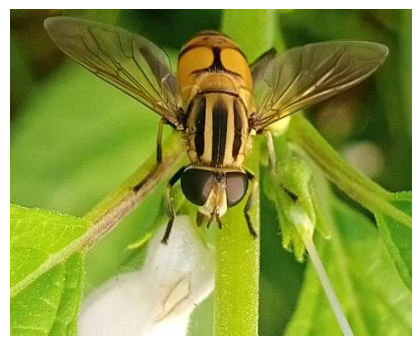

Eristalinus sp.

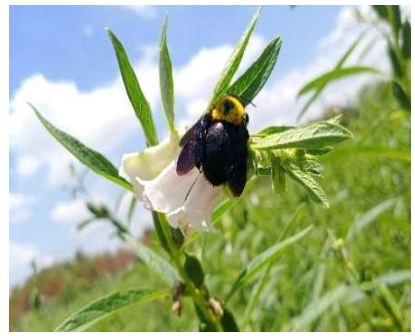

Xylocopa sp. 2

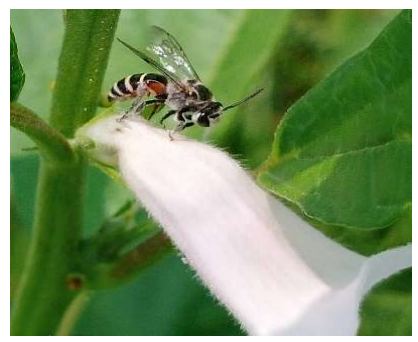

A. florea
Fig. 1. Major pollinators in sesamum at AC \& RI, Madurai

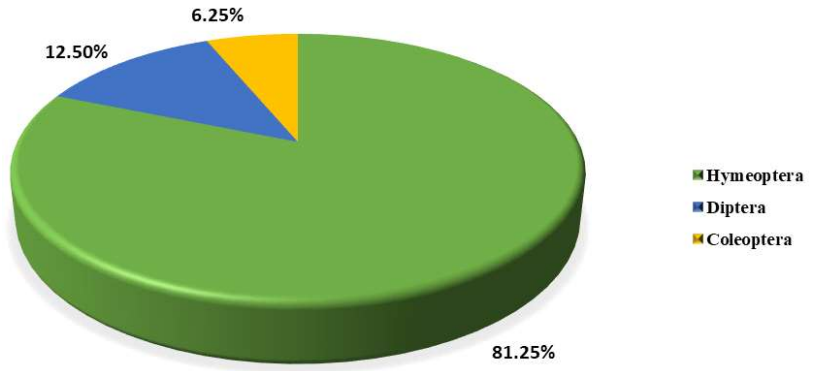

Fig. 2. Relative abundance of major pollinators of sesame at AC \& RI, Madurai

and maximum foraging rate of 12.6 florets/min at $1230-1330$ hours in Niger was recorded by Gebremedhm et al (2014). Bhagwati and Rahman (2016) observed number of flowers visited by $A$. cerana was maximum) during $0500-0600$ hours and minimum at 1600-1700 hours in sesame while our present study recorded maximum foraging by $A$. c. indica was at 1000-1200 hours and minimum at 1600-1800 hours. This may vary due to the difference in the observations in different time period and made evident as the increase in sunshine hours will decrease the visitation frequency. Vishwakarma and Chand. (2017) concluded that foraging rate of insect pollinators in forenoon hours was 1.5-1.7 times higher than in afternoon hours in mustard. Ahmad et al. (2018) documented the maximum visitation of sunflower heads was at 0900 hours by $A$. mellifera while the Xylocopa visited maximum at $1300-1700$ hours .

Foraging speed: $A$. florea spent maximum time of 18.05 $\mathrm{sec} /$ flower on sesame. However, A. c. indica and A. dorsata spent 15.04 and $11.14 \mathrm{sec} /$ flower at $0600-0800$ hours for foraging on sesame flowers. This might be due to either low visitation of flowers, availability of maximum pollen and nectar source in the morning hours (Table 6). Even as they visited minimum flowers at $1400-1600$ hours, the time spent by $A$. dorsata and $A$. florea tend to decline at $1600-1800$ hours (4.15 and $3.30 \mathrm{sec} /$ flower respectively) while the $A$. c. indica spared $3.31 \mathrm{sec} /$ flower. On observing the time spent by bees in evening hours, very low amount of pollens sticked on their bodily hairs. As soon as completion of peak anthesis period in the morning hours, the pollens started to dehisce and the sesame flowers ran out of floral rewards gradually from afternoon to evening hours. Bhagwati and Rahman (2016) quoted that maximum time spent per flower by $A$. cerana was 6.83 seconds during $0900-1000$ hours and minimum was 3.87 seconds during $1600-1700$ hours of the day. Kaur et al. (2021) stated that the mean foraging speed of A. mellifera was 4.42 seconds compared to $A$. cerana (4.10 seconds) and $A$. dorsata (3.53 seconds) in mustard. In sunflower, $A$. mellifera spent $60.97,74.46$ and 62.12 seconds 
Table 4. Relative abundance of pollinators during different flowering period in sesamum

\begin{tabular}{|c|c|c|c|c|c|c|}
\hline \multirow[t]{2}{*}{ Pollinators } & \multicolumn{5}{|c|}{ Abundance of pollinators during different flowering period of sesamum (No. of individuals $/ \mathrm{m}^{2} / 5 \mathrm{~min}$ ) } & \multirow[t]{2}{*}{ Abundance (\%) } \\
\hline & $15 \%$ flowering & $50 \%$ flowering & $100 \%$ flowering & $<50 \%$ flowering & Mean & \\
\hline A. c. indica & 3.41 & 7.68 & 9.03 & 5.48 & 6.40 & 22.44 \\
\hline A. dorsata & 5.03 & 7.89 & 8.82 & 6.47 & 7.05 & 24.72 \\
\hline A. florea & 2.06 & 4.31 & 5.07 & 1.45 & 3.22 & 11.29 \\
\hline Ceratina sp. & 0.61 & 1.09 & 1.41 & 0.35 & 0.86 & 3.01 \\
\hline A. zonata & 0.52 & 2.09 & 2.73 & 0.92 & 1.56 & 5.47 \\
\hline Braunsapis sp. & 0.68 & 2.16 & 2.59 & 0.57 & 1.50 & 5.26 \\
\hline Xylocopa sp. 1 & 0.23 & 0.85 & 0.91 & 0.0 & 0.49 & 1.71 \\
\hline Xylocopa sp. 2 & 0.17 & 0.81 & 0.92 & 0.0 & 0.47 & 1.64 \\
\hline M. lanata & 0.21 & 0.71 & 0.85 & 0.13 & 0.47 & 1.64 \\
\hline M. disjuncta & 0.23 & 0.56 & 0.78 & 0.08 & 0.41 & 1.43 \\
\hline Halictus sp. & 1.19 & 2.15 & 2.85 & 1.57 & 1.94 & 6.80 \\
\hline Nomia sp. & 0.44 & 1.17 & 1.65 & 0.46 & 0.93 & 3.26 \\
\hline Unidentified & 0.14 & 0.67 & 0.82 & 0.11 & 0.43 & 1.50 \\
\hline Eristalinus sp. & 0.45 & 1.28 & 1.82 & 0.37 & 0.98 & 3.43 \\
\hline Episyrphus sp. & 0.38 & 2.14 & 2.25 & 0.53 & 1.32 & 4.62 \\
\hline O. versicolor & 0.17 & 0.38 & 1.05 & 0.14 & 0.43 & 1.50 \\
\hline Mean & 15.92 & 35.94 & 43.55 & 18.63 & 28.51 & 100 \\
\hline
\end{tabular}

Table 5. Foraging rate of different Apis bees on sesame flowers during different hours of the day

\begin{tabular}{lccccccc}
\hline & \multicolumn{5}{c}{ No. of flowers visited/min* } & \multicolumn{3}{c}{ Mean } \\
\cline { 2 - 7 } & $0600-0800$ & $0800-1000$ & $1000-1200$ & $1200-1400$ & $1400-1600$ & $1600-1800$ \\
\hline A. dorsata & $5.30^{\mathrm{b}}$ & $7.44^{\mathrm{a}}$ & $6.18^{\mathrm{b}}$ & $4.74^{\mathrm{c}}$ & $2.46^{\mathrm{d}}$ & $3.18^{\mathrm{e}}$ & 4.88 \\
A. c. indica & $4.23^{\mathrm{b}}$ & $9.14^{\mathrm{a}}$ & $7.07^{\mathrm{b}}$ & $4.05^{\mathrm{d}}$ & $5.13^{\mathrm{c}}$ & $3.12^{\mathrm{e}}$ & 5.45 \\
A. florea & $3.21^{\mathrm{c}}$ & $4.02^{\mathrm{b}}$ & $5.95^{\mathrm{a}}$ & $3.07^{\mathrm{c}}$ & $2.32^{\mathrm{d}}$ & $1.54^{\mathrm{e}}$ & 3.35 \\
\hline
\end{tabular}

In a row, means followed by same letter(s) are not significantly different from each other, DMRT (P $\leq 0.05)$

Table 6. Foraging speed of different Apis bees on sesame flowers during different hours of the day

\begin{tabular}{|c|c|c|c|c|c|c|c|c|}
\hline \multirow{2}{*}{\multicolumn{2}{|c|}{ Time/ pollinator }} & \multicolumn{6}{|c|}{ Time spent (sec/ flower)* } & \multirow[t]{2}{*}{ Mean } \\
\hline & & $0600-0800$ & $0800-1000$ & $1000-1200$ & $1200-1400$ & $1400-1600$ & $1600-1800$ & \\
\hline A. & dorsata & $11.14^{\mathrm{a}}$ & $10.21^{\mathrm{b}}$ & $9.24^{c}$ & $5.90^{d}$ & $5.23^{\mathrm{e}}$ & $4.15^{f}$ & 7.64 \\
\hline A. & c. indica & $15.04^{\mathrm{a}}$ & $6.20^{\circ}$ & $8.12^{b}$ & $4.14^{d}$ & $3.31^{\mathrm{e}}$ & $8.03^{b}$ & 7.47 \\
\hline \multicolumn{2}{|c|}{ A. florea } & $18.05^{\mathrm{a}}$ & $14.18^{\mathrm{b}}$ & $11.14^{\mathrm{c}}$ & $10.49^{c}$ & $4.85^{\mathrm{d}}$ & $3.30^{\mathrm{e}}$ & 10.33 \\
\hline
\end{tabular}

Figures in the parenthesis are square root transformed values.

In a row, means followed by same letter(s) are not significantly different from each other, DMRT $(P \leq 0.05)$

per flower compared to $X$. fenesterata 66.65, 68.19 and 67.79 seconds during different sunshine hours_viz., 0900, 1300 and 1700 .

\section{CONCLUSION}

The present study concludes that $A$. dorsata and $A$. $C$. indica were the efficient pollinators of sesamum ecosystem as they played vital role in pollination with maximum foraging activity. By conserving the natural pollinators in sesame growing areas will definitely enhance its productivity.

\section{REFERENCES}

Ahmad M 2018. Diversity of sunflower insect pollinators and their foraging behavior under field conditions. Uludağ Arıcılık Dergisi 18(1): 14-27.

Azeez MA, Olowookere, Animasaun MB and Bello BO 2017. Utility of some floral characters in the assessment of genetic diversity in sesame (Sesamum indicum L.). Acta Agriculturae Slovenica 109(1): 61-70.

Bhagawati S, Rahman A and Deka MK 2016. Diversity of insect foragers with reference to foraging behaviour of Asian honey bee, Apis cerana F. on sesamum, Sesamum indicum L. Journal of Entomological Research 40(3): 213-216.

Das R and Jha S 2018. Record of insect pollinators and their 
abundance on Indian mustard (Brassica juncea L.) in New Alluvial Zone of West Bengal. International Journal of Pure and Applied Bioscience 6(5): 848-853.

Das R and Jha S 2019. Insect Pollinators of Sesame and the effect of entomophilous pollination on seed production in New Alluvial Zone of West Bengal. International Journal of Current Microbiology and Applied Sciences 8(3): 1400-1409.

Gebremedhn H and Tadesse A2014. Diversity of Guizotia abyssinica pollinators and their effect on seed quality in Mekelle, Northern Ethiopia. Livestock Research for Rural Development 26(11).

Kamel SM, Blal, Mahfouz AH and Said M 2013. The most common insect pollinator species on sesame crop (Sesamum indicum $L$.) in Ismailia Governorate, Egypt. Arthropods 2(2): 66.

Mahfouz AH, Kamel SM, Blal and Said M 2012. Pollinators visiting sesame (Sesamum indicum L.) seed crop with reference to foraging activity of some bee species. Cercetari Agronomice in
Moldova 45(2): 49-55.

Ngongolo K, Mtoka S and Rubanza CD 2015. Floral visitors and pollinators of sesame (Sesamum indicum L.) from Kichi forest to the adjacent local communities' farms. Entomology and Applied Science Letters 2(2): 32-39.

Pashte VV and Shylesha AN 2013. Pollinator diversity and their abundance on sesamum. Indian Journal of Entomology 75(3): 260-262.

Patidar BK, Ojha KN and Khan IU 2017. Role of honeybee (Apis mellifera) in enhancing yield of mustard in humid region of Rajasthan, India. International Journal of Current Microbiology and Applied Science 6(7): 1879-1882.

Vishwakarma $R$ and Chand $P$ 2017. Foraging activity of insect pollinators and their impact on yield of rapeseed-mustard. BIOINFOLET-A Quarterly Journal of Life Sciences 14(3): 222227. 